GRADIATION\&APPLICATIONS

ISSN 2466-4294 (online) | rad-journal.org

Vol. 2 | Issue 1 | pp. $71-74$

doi: 10.21175/RadJ.2017.01.016

Short note

\title{
THE EVALUATION OF THE SHORT TERM PHOTOSTABILITY OF THE ALPRAZOLAM DRUG*
}

\author{
Avni Berisha', Blerina Baxhaku', Nardi Sheqerxhiu'3, Ahmet Hoxha', \\ Nimet Orqusha ${ }^{3}$, Valbonë Mehmeti ${ }^{1}$, Ismet Hashani ${ }^{1}$, Jeton Halili ${ }^{* *}$, \\ Kaltrina Jusufi' ${ }^{1}$, Veprim Thaçi ${ }^{1}$, Adelina Halili ${ }^{2}$
}

\author{
1University of Pristina, Department of Chemistry, Pristina, Kosovo*** \\ ${ }^{2}$ University of Pristina, Department of Pharmacy, Pristina, Kosovo ${ }^{* * *}$ \\ 3Trepharm, Pristina, Kosovo ${ }^{* * *}$
}

\begin{abstract}
Alprazolam is a widely prescribed sedative and antidepressant benzodiazepine (BDZ) drug which belongs to the class of anxiolytic, sedative and hypnotic anticonvulsants. It is believed that alprazolam (ALP) is more fairly safe and it rapidly reduces the symptoms of anxiety through the control of the central nervous system (CNS) excitability by a selective and potent enhancement of inhibitory gammaamino butyric acid (GABA) mediated neurotransmission. Accelerated photochemical stability of alprazolam was performed under several conditions. The study involved the evaluation of the photostability of Alprazolam in active mater, in PVC/Aluminum blister packet (BPT) or without blister packet tablets (WBPT). The evaluation of the stability was performed using special stability test chambers at $60 \%$ controlled humidity, temperature and UV irradiation. The High-Performance Liquid Chromatography (HPLC) was used to analyze the content of the Alprazolam before and after UV irradiation. The obtained results for the short term photostability study do not show any significant degradation of this molecule by the UV irradiation in active mater and this holds true for the BPT or WBPT, independent of the Alprazolam content (o.25 or $0.50 \mathrm{mg}$ ).
\end{abstract}

Key words: Alprazolam, photostability, HPLC, benzodiazepine, drugs

\section{INTRODUCTION}

In general, the benzodiazepines are broadly recommended drugs that are used as anxiolytics, sedative hypnotics, anticonvulsants or muscle relaxants [1][2][3]. Aside from their therapeutic uses, benzodiazepines are frequently abused by drug addicts, so these drugs are often involved in both clinical and forensic cases. Alprazolam \{8-chloro-1-methyl-6phenyl-4H-s-triazol-o $(4,3-\mathrm{a})(1,4)$ benzodiazepine $\}$

(Fig.1) belongs to benzodiazepines and is used for treatment of panic disorders, anxiety, depression and sleeping disorders [1]. Alprazolam is one of the most prescribed benzodiazepines. This molecule is rapidly and completely absorbed after oral administration, and peak levels in plasma are taking place within 1-2 $\mathrm{h}$ after oral administration. It is rapidly absorbed and has a bioavailability of around $80-100 \%$ [4][2].<smiles>Cc1nnc2n1-c1ccc(Cl)cc1C(c1ccccc1)=NC2</smiles>

Figure 1. Chemical structure of Alprazolam (in blue is presented the benzodiazepine ring)

This molecule can be determined by a number of different methods such as: UV-VIS[5], TLC [6], GCMS[7], LC-EI-MS[8][9], LC-MS-MS[1], HPLC$\mathrm{TOF} / \mathrm{MS}[10]$ in different materials such as: pharmaceutical formulations[5], human plasma[8][9], oral fluids[10], hair [7], blood [11], urine[2], etc.

\footnotetext{
* The paper was presented at the Fourth International Conference on Radiation and Applications in Various Fields of Research (RAD 2016), Niš, Serbia, 2016.

** jetonhalilich@gmail.com

**** This definition does not prejudge the position of status in accordance with UNSC Resolution 1244 and the International Court of Justice on Kosovo's Declaration of Independence
} 
A. Berisha et al., The Evaluation of the Short Term Photostability..., Rad. Applic., 2017, 2, 1, 71-74

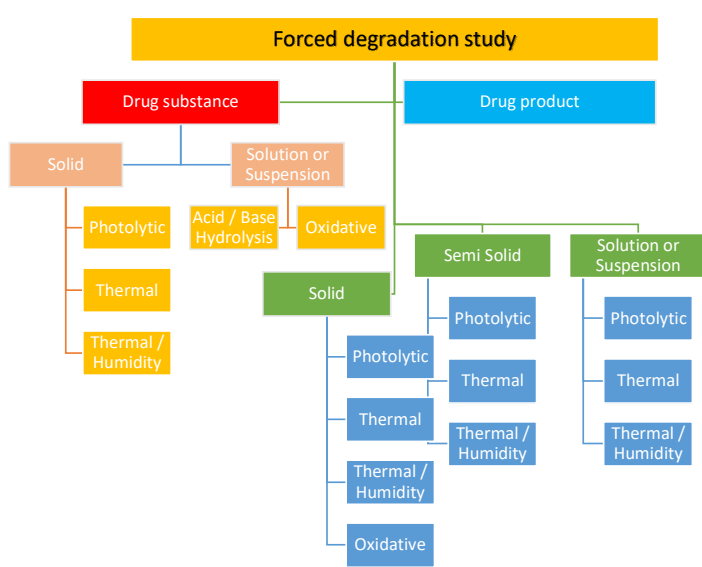

Figure 2. Flowchart describing several stress conditions used for degradation of drug substance and drug product

The stability of pharmaceutical molecules is a matter of great worry as it influences the safety and efficacy of the drug product [12]. Usually, different forced degradation (Fig 2) approaches are carried out to produce representative samples for developing stability-indicating methods for drug substances and drug products. Exposure of a drug to irradiation can affect the stability of the formulation, leading to changes in the physicochemical properties of the product [13]. The impact of excipients of frequently used stabilizers is frequently problematic to predict and, consequently, stability testing of the final preparation is important.

In our study, we evaluated the photostability of Alprazolam through the use of High-Performance Liquid Chromatography (HPLC) before and after UV irradiation.

\section{EXPERIMENTAL}

The content of Alprazolam was determined in three samples: active mater, and two different tablets containing Alprazolam (0.25 and $0.50 \mathrm{mg}$ ) BPT or WBPT ones. The High-Performance Liquid Chromatography (HPLC equipped with Diode Array Detector, Shimadzu USA MFG Inc.) was used to analyze the content of the Alprazolam before and after UV irradiation. The mobile phase was a 60:35:5 volume mixture of acetonitrile: buffer (phosphate $\mathrm{pH}=6$, prepared by dissolving 8.0 $\mathrm{g}$ of monobasic potassium phosphate and $2.0 \mathrm{~g}$ of dibasic potassium phosphate in $1 \mathrm{~L}$ of water): tetrahydrofuran (THF). Alprazolam was determined by the use of Ascentis Supelco 100A C8 column (5 $\mu \mathrm{m}$ particle size, 250x4.6 $\mathrm{mm}$ ), the flow rate was $1.0 \mathrm{~mL} / \mathrm{min}$ and $\mathrm{UV}$ detection was performed at $254 \mathrm{~nm}$. The samples were stored in CLIMATE CHAMBER (Memmert model ICH $110 \mathrm{~L}$ ) at $20{ }^{\circ} \mathrm{C}, 60 \%$ air humidity and exposed to UV irradiation (Fluorescent lights with cold-white light, standard illuminant D65, 6500 K, UV spectral range of $320-400 \mathrm{~nm}, 5 \mathrm{~W} / \mathrm{m}^{2}$, with Light intensity 6000 lux) for a corresponding period of time ( 3,6 and 9 days after UV irradiation). The calculations of Alprazolam were done using the equation below:

$$
m_{A l p} .[\mathrm{mg}]=\frac{\text { Peak. } S(\text { Sample }) * w(S t d) * w(\text { tablet }) * V(\text { sample }) * M(\text { sample })}{\text { Peak.S(Std. }) * w(\text { sample }) * V(S t d) * M(S t d)}
$$

\section{RESULTS AND DISCUSSION}

In Fig. 3, the calibration curve obtained for Alprazolam standard (from 10 to $100 \mathrm{ppm}$ ) is presented.

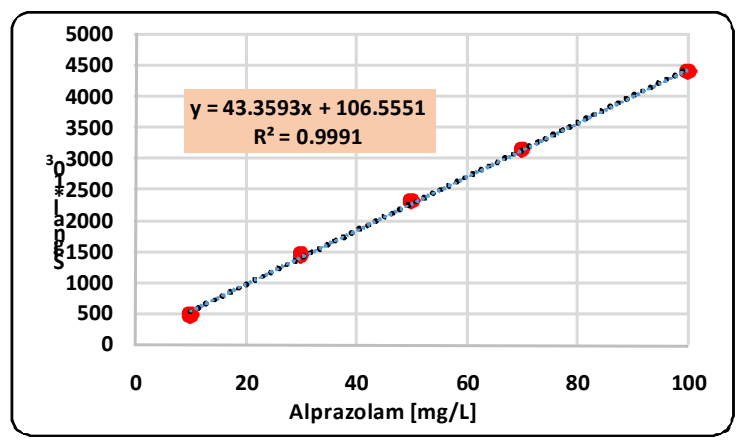

Figure 3. Calibration curve for Alprazolam determination at concentration 1 to $10 \mathrm{ppm}$ (the point represents the signal of the mean value for three consecutive injections of the same

concentration) [Conditions: $\mathrm{C}-8$ column, mobile phase 60:35:5 acetonitrile: buffer (phosphate $\mathrm{pH}=6$ ):

tetrahydrofuran (THF), UV detection at $254 \mathrm{~nm}$ ].

It can be easily seen from the curve regression coefficient that the correlation of the signal with the concentration of Alprazolam is almost unity, giving a possibility to precisely determine this molecule.

The retention time of the Alprazolam molecule determined with the conditions mentioned in the section of the experimental part is $9.642 \mathrm{~min}$. To verify the reproducibility of the used method, the values of six consecutive injections of $50 \mathrm{ppm}$ Alprazolam were analyzed and the obtained results are presented in Table 1.

Table 1. Results for the 6 injections of 50 ppm Alprazolam (retention time, mean value, standard deviation and RSD). C8 column, mobile phase 60:35:5 acetonitrile: buffer (phosphate $\mathrm{pH}=6)$ : tetrahydrofuran $(\mathrm{THF}), \mathrm{UV}$ detection at $254 \mathrm{~nm}$.

\begin{tabular}{ccc}
\hline Injection & $\begin{array}{c}\text { Retention time } \\
\text { (min) }\end{array}$ & Peak surface \\
\hline $\mathbf{1}$ & 9.642 & 2493287 \\
\hline $\mathbf{2}$ & 9.645 & 2497144 \\
\hline $\mathbf{3}$ & 9.644 & 2498008 \\
\hline $\mathbf{4}$ & 9.644 & 2498008 \\
\hline $\mathbf{5}$ & 9.638 & 2498016 \\
\hline $\mathbf{6}$ & 9.639 & 2497631 \\
\hline Mean value & 9.642 & 2497016 \\
\hline $\begin{array}{l}\text { Standard } \\
\text { deviation }\end{array}$ & 0.002646 & 1696.476 \\
\hline RSD & $0.03 \%$ & $0.07 \%$ \\
\hline
\end{tabular}

From the measurements, it is evident that the method utilized for the determination of Alprazolam fulfills the statistical criteria and is reliable, thus the same experimental parameters were used for further 
photostability measurements of this molecule in active matter, BPT of Alprazolam and WBPT Alprazolam tablets.

Small deviations regarding the original \% of Alprazolam are possibly linked to small standard deviations which are expected due to reproducibility, repeatability or even matrix effect of the sample.

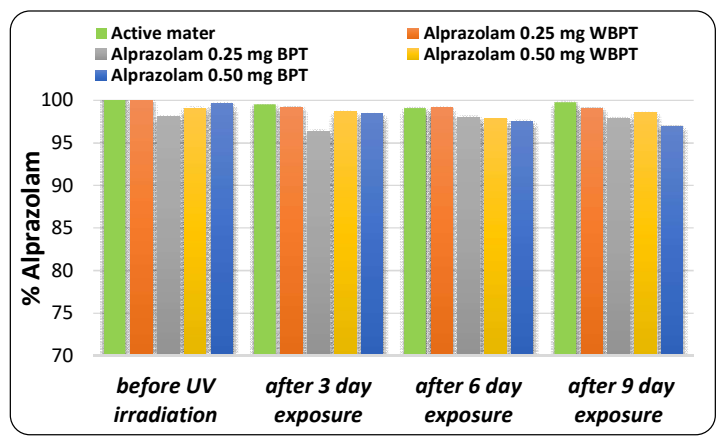

Figure 4. Summarized photo stability results for the Alprazolam molecule in active matter, and BPT or WBPT (0.25 and $0.5 \mathrm{mg}$ ) before and after UV irradiation for: 3, 6 and 9 day period. C-8 column, mobile phase 60:35:5 acetonitrile: buffer (phosphate $\mathrm{pH}=6$ ): tetrahydrofuran

(THF), UV detection at $254 \mathrm{~nm}$.

The results obtained for the photo stability test are summarized in Fig. 4. and show that the UV irradiation of the Alprazolam had no observed impact on the photo degradation of this molecule neither in the active matter, in the BPT or WBPT (containing 0.25 or 0.50 $\mathrm{mg}$ ).

\section{CONCLUSIONS}

HPLC method with UV detection has been successfully employed for the determination of the Alprazolam molecule in active matter and (W)BPT tablets containing different amounts of this molecule. The utilized method is shown to be reliable / being linear accurate and precise. The short-term photostability test showed that the chemical structure of this molecule in this time period remains unaltered. This remains true for each case, meaning that the coating or the weight of Alprazolam did not have any negative effect regarding the possible induction of any photolytic degradation/reaction path of this molecule. Although this short photostability in fact is a stress test, in order to properly and safely evaluate the stability test apart from the time period increase of the test, one should also perform other stability tests (thermal, acid/base hydrolysis, etc.) to get a full evaluation of the molecules stability.

\section{REFERENCES}

1. S. J. Marin, R. Coles, M. Merrell, and G. A. McMillin, "Quantitation of benzodiazepines in urine, serum, plasma, and meconium by LC-MS-MS," J. Anal. Toxicol., vol. 32, no. 7, pp. 491-498, 2008.

DOI: $10.1093 / \mathrm{jat} / 32.7 .491$

PMid: 18713517
2. S. Karampela, I. Vardakou, I. Papoutsis, A. Dona, C. Spiliopoulou, S. Athanaselis, and C. Pistos, "Direct urine analysis for the identification and quantification of selected benzodiazepines for toxicology screening," $J$. Chromatogr. B. Analyt. Technol. Biomed. Life Sci., vol. 902, pp. 42-46, 2012.

DOI: 10.1016/j.jchromb.2012.06.012 PMid: 22790390

3. G. Ngwa, D. Fritch, K. Blum, and G. Newland, "Simultaneous analysis of 14 benzodiazepines in oral fluid by solid-phase extraction and LC-MS-MS," $J$. Anal. Toxicol., vol. 31, no. 7, pp. 369-376, 2007.

DOI: $10.1093 / \mathrm{jat} / 31.7 .369$ PMid: 17725884

4. D. J. Greenblatt and C. E. Wright, "Clinical pharmacokinetics of alprazolam. Therapeutic implications," Clin. Pharmacokinet., vol. 24, no. 6, pp. 453-471, 1993.

DOI: 10.2165/00003088-199324060-00003 PMid: 8513649

5. A. Mohd, A. A. Parwaz Khan, S. Bano, and K. S. Siddiqi, "UV-absorption and fluorimetric methods for the determination of alprazolam in pharmaceutical formulation," Arab. J. Chem., vol. 6, no. 4, pp. 369378, 2013.

DOI: 10.1016/j.arabjc.2010.10.013

6. U. K. Chhalotiya, N. M. Patel, D. A. Shah, F. A. Mehta, and K. K. Bhatt, "Thin-layer chromatography method for the simultaneous quantification and stability testing of alprazolam and mebeverine in their combined pharmaceutical dosage form," J. Taibah Univ. Sci., vol. 11, no. 1, pp. 66-75, Jan. 2017. DOI: 10.1016/j.jtusci.2015.06.012

7. K. M. Höld, D. J. Crouch, D. G. Wilkins, D. E. Rollins, and R. A. Maes, "Detection of alprazolam in hair by negative ion chemical ionization mass spectrometry," Forensic Sci. Int., vol. 84, no. 1-3, pp. 201-209, 1997. DOI: 10.1016/So379-0738(96)02063-4

8. O. Quintela, P. López, A. M. Bermejo, and M. LópezRivadulla, "Determination of methadone, 2-ethylidene1,5-dimethyl-3,3-diphenylpyrrolidine and alprazolam in human plasma by liquid chromatography-electrospray ionization mass spectrometry," J. Chromatogr. B. Analyt. Technol. Biomed. Life Sci., vol. 834, no. 1-2, pp. 188-194, 2006.

DOI: 10.1016/j.jchromb.2006.02.013 PMid: 16517229

9. A. Allqvist, A. Wennerholm, J.-O. Svensson, and R. A. Mirghani, "Simultaneous quantification of alprazolam, 4- and alpha-hydroxyalprazolam in plasma samples using liquid chromatography mass spectrometry," $J$. Chromatogr. B. Analyt. Technol. Biomed. Life Sci., vol. 814, no. 1, pp. 127-131, 2005.

DOI: $10.1016 /$ j.jchromb.2004.10.012 PMid: 15607716

10. D. Di Corcia, S. Lisi, V. Pirro, E. Gerace, A. Salomone, and M. Vincenti, "Determination of pharmaceutical and illicit drugs in oral fluid by ultra-high performance liquid chromatography-tandem mass spectrometry," $J$. Chromatogr. B. Analyt. Technol. Biomed. Life Sci., vol. 927, pp. 133-141, 2013.

DOI: $10.1016 /$ j.jchromb.2013.01.025

PMid: 23433923

11. I. I. Papoutsis, S. A. Athanaselis, P. D. Nikolaou, C. M. Pistos, C. A. Spiliopoulou, and C. P. Maravelias, "Development and validation of an EI-GC-MS method for the determination of benzodiazepine drugs and their metabolites in blood: applications in clinical and forensic toxicology," J. Pharm. Biomed. Anal., vol. 52, no. 4, pp. 609-614, 2010.

DOI: 10.1016/j.jpba.2010.01.027

PMid: 20172681 
A. Berisha et al., The Evaluation of the Short Term Photostability..., Rad. Applic., 2017, 2, 1, 71-74

12. M. Blessy, R. D. Patel, P. N. Prajapati, and Y. K. Agrawal, "Development of forced degradation and stability indicating studies of drugs-A review," $J$. Pharm. Anal., vol. 4, no. 3, pp. 159-165, 2014.

DOI: $10.1016 /$ j.jpha.2013.09.003
13. H. H. Tønnesen, "Formulation and stability testing of photolabile drugs," Int. J. Pharm., vol. 225, no. 1-2, pp. 1-14, 2001.

DOI: 10.1016/So378-5173(01)00746-3 